\title{
Obesidade e sedentarismo no ensino médio: uma proposta de intervenção nas aulas de educação física
}

\author{
Wellington Lima da Silva ${ }^{1}$ \\ Luiz Felipe Chaves Pereira ${ }^{2}$ \\ Marcos Vinicius Francisco ${ }^{3}$
}

Resumo: Nesta pesquisa assumiram-se como objetivos sistematizar e desenvolver uma proposta de intervenção que auxiliasse os/as estudantes do ensino médio a refletirem criticamente sobre os temas da obesidade e do sedentarismo. Os/as participantes da pesquisa interventiva, estudantes de uma turma do $2^{\circ}$ ano do ensino médio, frequentavam uma escola da rede pública estadual, de um município de médio porte, do interior do estado de São Paulo. A metodologia de ensino crítico-superadora em Educação Física, vinculada à perspectiva teórica da pedagogia histórico-crítica, subsidiou a práxis pedagógica. Em um primeiro momento, foram apresentados dados científicos de pesquisas que os/as levaram a refletirem sobre a construção da desigualdade social no contexto brasileiro e os impactos no processo de apropriação dos alimentos e do exercício físico por parte da classe trabalhadora. Posteriormente, os conceitos de obesidade e sedentarismo foram apresentados na perspectiva teórica assumida. Após, aplicou-se o questionário do Bem Estar, além de realizar a aferição dos dados do Índice de Massa Corporal (IMC) dos/as estudantes, na expectativa de problematizá-los. Os resultados apontaram que os/as estudantes optam por alimentos ricos em calorias e pobres em nutrientes, alimentos prejudiciais à saúde. Poucos/as são os/as que realizam ao menos cinco refeições diárias. Uma pequena parcela, frequentemente, realiza atividades físicas. Tais dados, assim como os conceitos de obesidade e sedentarismo, foram contextualizados, a partir de uma leitura crítica dos determinantes históricos, sociais e culturais que exercem influências nesse processo. Sobretudo, porque os argumentos dos/as estudantes, ao estarem pautados no senso comum, coadunam com a lógica de culpabilização e responsabilização exclusiva, pela condição de saúde que se encontram, bem como de seus familiares.

Palavras - chave: Educação Física escolar. Obesidade. Sedentarismo. Metodologia de Ensino CríticoSuperadora. Pedagogia histórico-crítica.

\section{Obesity and sedentarism in high school: a proposal for intervention proposal in physical education classes}

\footnotetext{
${ }^{1}$ Licenciado em Educação Física pela Universidade do Oeste Paulista (Unoeste), Programa Especial de Iniciação Científica (PEIC/Unoeste). Atualmente cursa bacharelado em Educação Física na Universidade Estadual Paulista (Unesp), campus de Presidente Prudente-SP. E-mail: wellingtonls_@outlook.com

${ }^{2}$ Licenciado em Educação Física pela Universidade do Oeste Paulista (Unoeste), Programa Especial de Iniciação Científica (PEIC/Unoeste). Atua como professor de Educação Física na Secretaria Municipal de Educação de Presidente Epitácio. E-mail: felipe_flp96@hotmail.com

${ }^{3}$ Doutor em Educação pela Universidade Estadual Paulista (Unesp), campus de Presidente Prudente-SP. Atualmente, é docente permanente do Programa de Pós-Graduação em Educação e do curso de Educação Física da Universidade do Oeste Paulista (Unoeste); docente permanente do Programa de Pós-Graduação em Educação da Universidade Estadual de Maringá (UEM) e do curso de Educação Física do Campus Regional do Vale do Ivaí (UEM/CRV). E-mail: marcos_educa01@yahoo.com.br
} 


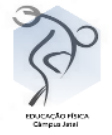

Abstract: This research, has taken as goals to systematize and develop a proposal for intervention which would help high school students to critically reflect about the topics of obesity and sedentarism. Participants in this interventive research, that is, students from a second-year high school class, who attended a school from the public state network, in a medium-sized municipality located in the state of São Paulo countryside. Pedagogical praxis was grounded on the critical-overcoming teaching methodology in Physical Education, linked to the theoretical perspective of historical-critical pedagogy. In the first moment, scientific research data were presented, leading them to reflect on the construction of social inequality in the Brazilian context and the impacts on the appropriation process of food and physical exercise by the working class. Subsequently, the concepts of obesity and sedentarism were presented in the theoretical perspective assumed. Afterwards, the Well-Being questionnaire was applied, in addition to carrying out the measurement of the students' Body Mass Index (BMI), with the aim to problematize them. Results pointed out that students opt for foods rich in calories and poor in nutrients, foods that are harmful to health. Few are those who have at least five meals a day. A small portion, frequently, performs physical activities. Such data, as well as the concepts of obesity and sedentarism, were contextualized, based on a critical reading of historical, social and cultural determinants that exert influences in this process. Mostly, because students' arguments, when grounded on common sense, are consistent with the logic of exclusive blaming and accountability, due to the health condition they currently have, as well as that of their families.

Keywords: School Physical Education. Obesity. Sedentarism. Critical-Overcoming Teaching Methodology. Historical-critical pedagogy.

\section{INTRODUÇÃO}

A obesidade e o sedentarismo tiveram um aumento considerável, entre as populações de jovens, se comparado às décadas anteriores (CUREAU et al., 2012; SILVA JUNIOR, 2012; PINHO; BOTELHO; CALDEIRA, 2014; NOGUEIRA et al., 2014; CARNEIRO et al., 2017). De acordo com Carneiro et al. (2017), a prevalência da obesidade não é um problema exclusivo dos países desenvolvidos ou em desenvolvimento, ela também é realidade nos países pobres que sofrem de desnutrição e insegurança alimentar, decorrente da desigualdade social (BARATA, 2009; CARNEIRO et al., 2017).

Ao analisar os conceitos de obesidade e sedentarismo, longe de assumir uma visão biologicista e de responsabilização individual, entende-se que "os mesmos processos que determinam a estruturação da sociedade são aqueles que geram as desigualdades sociais e produzem os perfis epidemiológicos de saúde e doença” (BARATA, 2009, p. 23). Complementa Barata (2009, p. 24), “o sistema de reprodução social dos diferentes grupos inclui os padrões de trabalho e consumo, as atividades práticas da vida cotidiana, as formas organizativas ou de participação social, a política e a cultura”. Ou seja, por meio das 


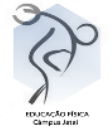

contradições expressas nas sociedades, é que os indivíduos, conforme sua posição social terão distintas possibilidades de apropriação das objetivações produzidas historicamente pelo gênero humano, sejam às ligadas aos processos benéficos mantenedores de saúde ou aos processos produtores de doenças (BARATA, 2009; BAGRICHEVSKY et al., 2013; NOGUEIRA et al., 2014).

Para Pinheiro, Freitas e Corso (2004, p. 523) "a obesidade, doença integrante do grupo de Doenças Crônicas Não-Transmissíveis, é o acúmulo excessivo de gordura corporal em extensão tal, que acarreta prejuízos à saúde dos indivíduos”. Distúrbios do aparelho locomotor, problemas dermatológicos e dificuldades respiratórias podem ser citados como prejuízos correlacionados à obesidade (ORGANIZAÇÃO PAN-AMERICANA DE SAÚDE, 2003; PINHEIRO; FREITAS; CORSO, 2004; GARCIA JUNIOR, 2007; CASTRO et al., 2018), além de culminar com o surgimento de enfermidades letais, tais como as doenças cardiovasculares, as dislipidemias, o Diabetes Não-Insulino-Dependente (Diabetes Tipo II) e certos tipos de câncer (OMS, 1997; ORGANIZAÇÃO PAN-AMERICANA DE SAÚDE, 2003; PALMA, 2008; CASTRO et al., 2018). Poulain (2013) reforça, além de ser um problema de saúde pública, a obesidade corrobora, também, como um problema de estigmatização, daí a necessidade de ser visibilizada diante de sua dimensão social.

No que tange a etiologia da obesidade, ela deve ser analisada como um processo multifatorial que envolve aspectos ambientais e genéticos (PINHEIRO; FREITAS; CORSO, 2004, BARBOSA, 2008; TAVARES; NUNES; SANTOS, 2012; NOGUEIRA et al., 2014; CASTRO et al., 2018). Talvez, seja o maior problema que as sociedades estejam enfrentando, para além da desnutrição (BARBOSA, 2008).

Para Barbosa (2008) e Castro et al., (2018), o sedentarismo, combinado com as atividades físicas de baixa intensidade, tais como o uso de celulares, computadores, videogames e o tempo gasto assistindo televisão têm contribuído para o aumento de peso dos jovens. Complementa Caballero (2007) e Alves et al. (2018), esse tipo de atividades de baixo gasto calórico, associado ao consumo de alimentos de alto valor energético e baixo valor nutritivo é de grande influência, respectivamente, para o aparecimento do sedentarismo e da obesidade. Há que se ponderar que os grandes centros urbanos impõem enormes restrições à 


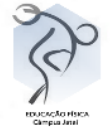

atividade física espontânea, pelo fato da insegurança e violência se fazerem intensas (OMS, 2000; BARBOSA, 2008).

Diante de tais elementos, as seguintes problemáticas sustentaram esta investigação de caráter interventivo: A Educação Física contribui de que maneira no enfrentamento da obesidade e do sedentarismo junto aos estudantes? Os estudantes do ensino médio têm ciência do que sejam a obesidade e o sedentarismo? O ensino sobre obesidade e sedentarismo presente no currículo do estado de São Paulo é suficiente para estimular os estudantes do ensino médio a adotarem hábitos saudáveis?

Assumiu-se como hipótese que a Educação Física escolar pode contribuir no processo de prevenção à obesidade e ao sedentarismo, ao estimular os estudantes a adotarem hábitos mais saudáveis. Contudo, tais discussões não podem acontecer de forma descontextualizada, sem articulação com os aspectos que favorecem a produção da desigualdade social, visto que nem todos têm condições de se alimentar adequadamente, seja em âmbito quantitativo e qualitativo ou de se exercitarem nos momentos de lazer.

Frente aos aspectos supracitados, assumiram-se como objetivos sistematizar e desenvolver uma proposta de intervenção que auxiliasse os estudantes do ensino médio a refletirem criticamente sobre os temas da obesidade e do sedentarismo.

\section{METODOLOGIA}

A presente pesquisa de natureza interventiva assenta-se na perspectiva da metodologia de ensino crítico superadora em Educação Física (CASTELLANI FILHO et al., 2012; TAFFAREL, 2016), que tem como base teórica a pedagogia histórico-crítica (SAVIANI, 2012; MARSIGLIA; MARTINS; LAVOURA, 2019). A intenção não foi apenas coletar dados e discuti-los, mas também mobilizar os/as estudantes participantes da pesquisa a refletirem sobre os temas da obesidade e do sedentarismo, por meio de atividades formativas de caráter interventivo.

A metodologia de ensino crítico-superadora, ancorada na pedagogia históricocrítica, assume uma concepção escolar, por meio da qual se destaca a função social da Educação Física. O conhecimento científico nessa perspectiva deve levar o estudante a 


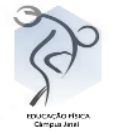

ultrapassar o senso comum e construir formas mais elaboradas de pensamento, a fim de que as vivências e reflexões produzidas por intermédio da práxis-pedagógica possam ser apropriadas e objetivadas (CASTELLANI FILHO et al., 2012; SAVIANI, 2012; TAFFAREL, 2016; MARSIGLIA; MARTINS; LAVOURA, 2019).

De acordo com Castellani Filho et al. (2012), a práxis-pedagógica deve ter sentido e significado para os estudantes, de tal forma que eles consigam compreender as relações entre as diferentes manifestações da cultura corporal, em articulação com os grandes problemas produzidos historicamente, socialmente e culturalmente, dentre eles a desigualdade de acesso aos bens produzidos pela humanidade. Essa reflexão vai ao encontro das necessidades dos/as estudantes da escola pública, a fim de que consigam apreender a realidade social, interpretando-a conforme os seus interesses de classe.

Tal lógica sustenta-se nos fundamentos didáticos da pedagogia histórico-crítica (SAVIANI, 2012), ou seja, está pautada na lógica dialética, diante do movimento contraditório e de totalidade que vai da síncrese à síntese pela mediação da análise (MARSIGLIA; MARTINS; LAVOURA, 2019). Saviani (2012), ao analisar o movimento presente na prática pedagógica, elucida cinco passos, os quais não podem ser visualizados de maneira estanque ou didatizados a procedimentos de ensino (MARSIGLIA; MARTINS; LAVOURA, 2019). A Prática Social, “comum a professor e alunos", é o ponto de partida (SAVIANI, 2012, p. 70). Do ponto de vista pedagógico, os/as alunos/as e professores/as estão em níveis distintos de compreensão da prática social, em termos de conhecimento e experiência. Os/As professores/as apresentam uma síntese precária e os/as estudantes uma compreensão sincrética da realidade. Num segundo momento - Problematização - há que se identificar os principais problemas postos pela prática social. "Trata-se de detectar que questões precisam ser resolvidas no âmbito da prática social e, em consequência, que conhecimento é necessário dominar" (SAVIANI, 2019, p. 71).

Dialeticamente, o terceiro passo - Instrumentalização - coaduna com a “apropriação dos instrumentos teóricos e práticos necessários ao equacionamento dos problemas detectados na prática social" (SAVIANI, 2012, p. 71). São materializadas como ferramentas culturais apropriadas pelos/as alunos/as, na expectativa de que sirvam como meio para auxiliar no enfrentamento das condições que vivenciam. Posteriormente, por meio da 


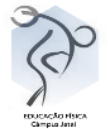

Catarse, compreendida na definição gramsciana de "elaboração superior da estrutura em superestrutura na consciência dos homens", ou seja, "trata-se da efetiva incorporação dos instrumentos culturais, transformados agora em elementos ativos de transformação social" (SAVIANI, 2012, p. 71). Por fim, a Prática Social que foi ponto de partida, também será o ponto de chegada, já não mais compreendida em termos sincréticos pelos/as alunos/as, pois estes/as ascenderão ao nível sintético, ou seja, da síncrese à síntese. Ao mesmo tempo, a compreensão dos/as professores/as se torna mais orgânica.

\subsection{Local e participantes}

Os participantes desta pesquisa interventiva foram estudantes de uma turma do $2^{\circ}$ ano do ensino médio, de uma escola da rede pública estadual, numa cidade de médio porte, do interior do estado de São Paulo, que atende a essa modalidade de ensino. Participaram da pesquisa interventiva, todos/as os/as estudantes que assentiram sua participação (Termo de Assentimento), bem como os/as que tiveram autorização de seus pais e/ou responsáveis (Termo de Consentimento Livre e Esclarecido - TCLE), em consonância com os aspectos éticos da pesquisa com seres humanos. O estudo foi aprovado pelo Comitê de Ética em Pesquisa $(\mathrm{CEP})^{4}$.

Vale apontar que, dos/as 26 estudantes vinculados à turma, 20 consentiram a participação na pesquisa interventiva. Essa série foi escolhida, justamente, por ser a que contempla os temas da obesidade, do sedentarismo e das doenças hipocinéticas no ensino médio, conforme o currículo do estado de São Paulo para a disciplina de Educação Física (SÃO PAULO, 2014). Já a referida unidade escolar foi selecionada por fazer parte de um projeto guarda-chuva conduzido pelo orientador desta investigação, aprovado quanto ao mérito junto ao Conselho Nacional de Desenvolvimento Científico e Tecnológico (CNPq).

\subsection{Intervenções}

\footnotetext{
${ }^{4}$ O Número do Certificado de Apresentação para Apreciação Ética (CAAE) é 71837417.3.0000.5515.
} 
$\mathrm{Na}$ primeira fase da pesquisa ocorreram intervenções em quatro aulas de Educação Física. Num primeiro momento, foram apresentados dados científicos de pesquisas e estudos que levaram os estudantes a refletirem sobre a construção da desigualdade social no contexto brasileiro, esta que impede parcela expressiva da população de se apropriar das objetivações produzidas pelo gênero humano, tais como alimentos, dimensões do lazer, recursos matérias entre outros (BARATA, 2009; CASTELLANI FILHO et al., 2012; DIAS et al., 2016; TAFFAREL, 2016). Posteriormente, os conceitos científicos de obesidade e sedentarismo foram apresentados e debatidos junto aos estudantes, a fim de que eles pudessem se apropriar dos referidos e compreender as influências dos aspectos sociais e culturais em sua dinâmica, bem como as implicações decorrentes (PALMA, 2008; BARATA, 2009; CARNEIRO et al., 2017). Para tanto, serviu como base as discussões do currículo do estado de São Paulo, vinculado à disciplina de Educação Física, com articulação ao tema corpo, saúde e beleza (SÃO PAULO, 2014; 2017, v. 2). Algumas adequações foram empreendidas, na expectativa de afunilar o tema na perspectiva aqui assumida, ou seja, em consonância com os determinantes sociais e culturais (SAVIANI, 2012; MARSIGLIA; MARTINS, LAVOURA, 2019).

Num segundo momento (conjunto de mais duas aulas) foram recolhidos os dados para o cálculo do Índice de Massa Corporal (IMC) ${ }^{5}$ dos estudantes e aplicado o questionário "Pentáculo do bem estar" de Nahas, Barros e Francalacci (2000). Conforme os autores do Pentáculo, a utilização do método do IMC, desenvolvido pelo polímata Lambert Quetelet (1832), deveu-se ao fato de ser de rápida avaliação, de baixo custo e fácil de ser aplicado. O IMC aponta o nível do estado nutricional do indivíduo, bem como se o/a avaliado/a encontrase acima ou abaixo do peso ideal. De acordo com Ricardo e Araujo (2002), o índice de massa corporal (IMC) é definido matematicamente, como: peso $(\mathrm{kg}) / \operatorname{altura}^{2}(\mathrm{~m})$. Este método é adotado pela Organização Mundial da Saúde (OMS, 2000). Utilizou-se uma balança digital de vidro da marca Bioland, modelo eb-9010, com graduação de $0,1 \mathrm{~kg}$ e capacidade de $180 \mathrm{~kg}$ e

\footnotetext{
${ }^{5}$ Embora, de acordo com Pinheiro, Freitas e Corso (2004), o IMC não seja capaz de descrever a ampla variação na composição corporal de indivíduos, ao desconsiderar, por exemplo, a idade, a relação entre IMC e indicadores de composição corporal, tais como a gordura corporal, seu uso foi adotado por não requerer custos e equipamentos, na maioria das vezes, não disponíveis nas escolas públicas. Porém, para fins didáticos, o seu uso foi suficiente, além de ser um critério adotado pela OMS desde 1998.
} 


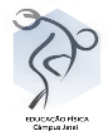

uma fita métrica, a fim de aproximar da realidade dos estudantes. Os resultados encontrados junto aos/as estudantes foram comparados com um quadro que classifica o IMC dos indivíduos, conforme apresenta a Tabela 1.

Tabela1. Classificação de adequação do peso de acordo com o IMC.

\begin{tabular}{cc}
\hline IMC & Classificação \\
\hline$<16$ & Magreza grave \\
$16 \mathrm{a}<17$ & Magreza moderada \\
$17 \mathrm{a}<$ & Magreza leve \\
18,5 & Saudável \\
$18,5 \mathrm{a}<$ & Sobrepeso \\
25 & Obesidade Grau I \\
$25 \mathrm{a}<30$ & Obesidade Grau II \\
$30 \mathrm{a}<35$ & (severa) \\
$35 \mathrm{a}<40$ & Obesidade Grau III \\
$>40$ & (mórbida) \\
\hline
\end{tabular}

Fonte: Organização Mundial de Saúde (2000)

Por sua vez, o Pentáculo do Bem Estar (PBE) é um questionário que avalia o perfil de estilo de vida (individual ou coletivamente). O questionário é composto por 5 (cinco) componentes: nutrição, atividade física, comportamentos preventivos, relacionamento social e controle de estresse, pois essas ações têm grande influência na saúde geral (NAHAS; BARROS; FRANCALACCI, 2000). No questionário há 15 (quinze) perguntas fechadas, sendo três de cada componente, já citado acima. As respostas correspondem a uma escala, sendo que o 0 (zero) equivale a afirmação de que "absolutamente não faz parte do seu estilo de vida (nunca)", 1 (um) corresponde ao comportamento, "às vezes", 2 (dois) equivale a "quase sempre" e 3 (três) "faz parte do seu comportamento" (NAHAS; BARROS; FRANCALACCI, 2000).

O Pentáculo é uma demonstração gráfica dos resultados obtidos, e a figura de um Pentáculo (estrela) facilita a visualização dos resultados. Na análise dos dados do Pentáculo, cada pergunta corresponde a uma letra, e o resultado de cada pergunta corresponde a um número. O resultado de cada pergunta é demarcado no Pentáculo, como se observa na Figura 1. 


\section{REFLECTIONIS}

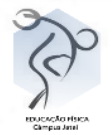

Figura 1: Pentáculo do Bem Estar

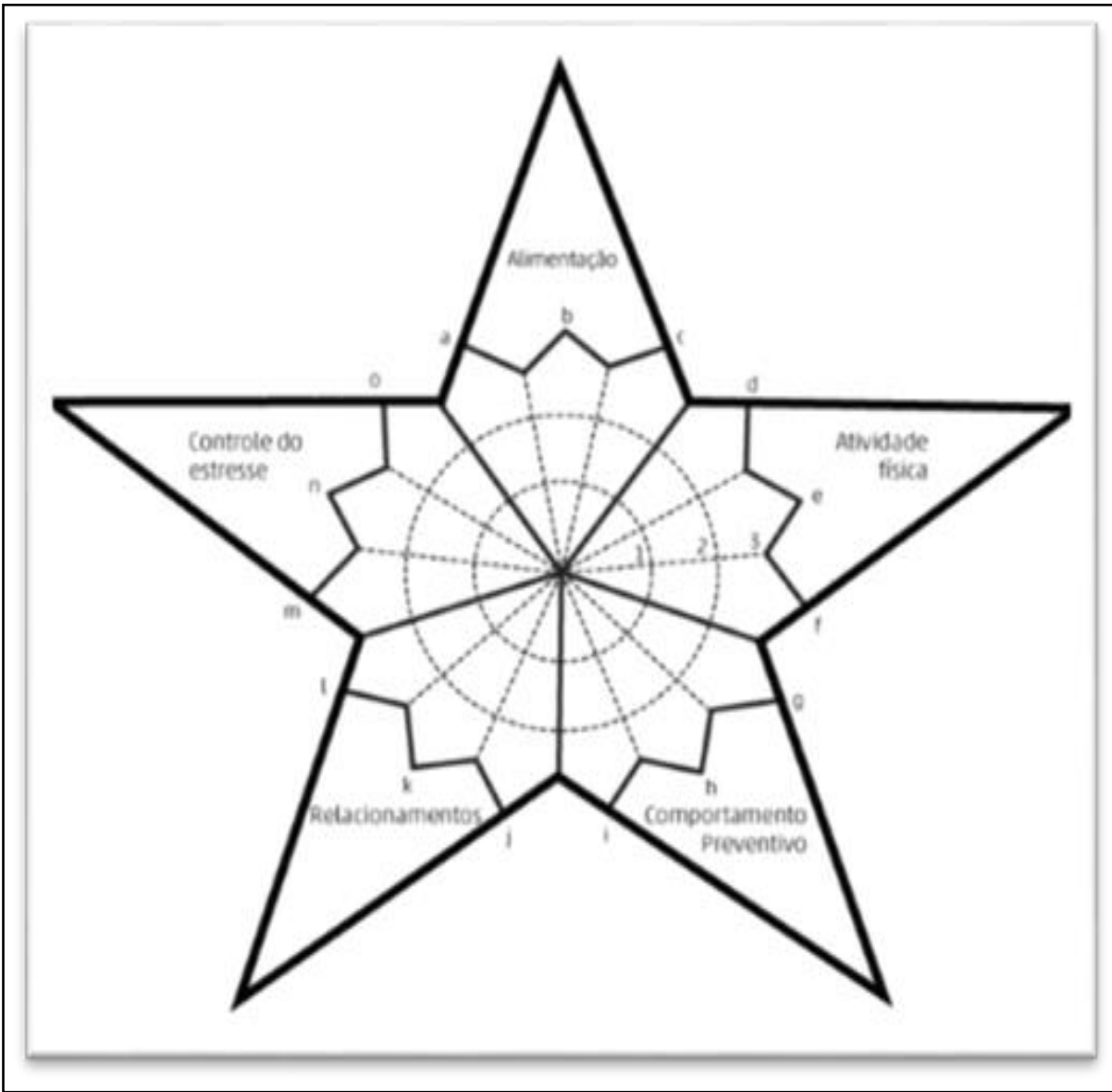

Fonte: Nahas, Barros e Francalacci (2000).

O Pentáculo é considerado um bom método para avaliar a qualidade de vida e a identificação dos aspectos que precisam ser melhorados na vida dos participantes, diante da adoção de hábitos mais saudáveis (NAHAS; BARROS; FRANCALACCI, 2000). Vale apontar que cada estudante recebeu o seu Pentáculo, após a tabulação dos dados. As interações ocorridas nesses diferentes momentos foram registradas, no diário de campo, por um dos pesquisadores.

Posteriormente, procedeu-se por um debate coletivo ${ }^{6}$ com os/as estudantes (duas aulas de Educação Física), a fim de problematizar os dados obtidos de forma geral. Foi

\footnotetext{
${ }^{6}$ Por falta de espaço, tais dados não serão problematizados neste artigo. Porém, optou-se apresentar as questões feitas, a fim de que os/as leitores tenham acesso à totalidade que originou esta pesquisa de caráter interventivo.
} 


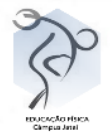

entregue um questionário com questões abertas para cada participante, com a intenção de saber: i) $\mathrm{O}$ que as intervenções significaram; ii) $\mathrm{O}$ que pensavam das situações promotoras da desigualdade social que, por conseguinte, favorecem ao aparecimento da obesidade e do sedentarismo; iii) $\mathrm{O}$ que não conheciam e passaram a conhecer com as atividades e discussões realizadas; iv) Na opinião dos/as participantes, quais foram os aspectos positivos e negativos da intervenção; v) E se havia alguma coisa que gostariam de contar. Os resultados das intervenções serão discutidos e analisados no próximo item deste artigo.

\section{RESULTADOS E DISCUSSÃO}

No primeiro conjunto de intervenções, ocorreram as apresentações de dados e de estudos científicos sobre a obesidade e o sedentarismo, além disso, foram discutidos e explicados, dialogicamente, os fatores que podem influenciar na produção dos casos de obesidade tais como: fatores genéticos, fisiológicos e culturais (MARQUES-LOPES et al., 2004; PALMA, 2008; BARATA, 2009; PINHEIRO; CARVALHO, 2010; CASTELLANI FILHO et al., 2012; DIAS et al., 2016; POULAIN, 2013; TAFFAREL, 2016; CARNEIRO et al., 2017).

Durante esse processo, alguns estudantes começaram a relatar casos de sobrepeso e obesidade na família, sempre com discursos de culpabilização dos familiares. Nesse sentido, para problematizar os discursos que se centram, apenas, na dimensão do desequilíbrio crônico entre a energia consumida e a energia gasta (CABALLERO, 2007), foi desenvolvida uma atividade, por meio da qual se distribuiu uma bala para cada estudante e, em seguida, foi perguntado se eles sabiam quantas calorias havia na bala? E o que eles deveriam fazer para metabolizar a mesma? Após ouvir todas as respostas dos/as estudantes, explicou-se sobre as relações entre consumo $\mathrm{X}$ gasto energético, e listaram-se algumas atividades que seriam necessárias, por exemplo, para metabolizar as calorias adquiridas por meio de alguns alimentos que são consumidos diariamente.

No que se refere à dimensão sociocultural, foram apresentados aspectos sobre a construção da desigualdade social, a fim de levar os/as estudantes à reflexão sobre o acesso e a disponibilidade a certos tipos de alimentos, o marketing elaborado pelas empresas 


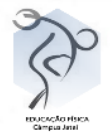

alimentícias, a influência da sociedade, da família e da mídia em relação à obesidade (PALMA, 2008; BARATA, 2009; DIAS et al., 2016; CARNEIRO et al., 2017). Além disso, debateu-se sobre os preconceitos e estigmas que as pessoas classificadas com sobrepeso ou obesidade enfrentam, por meio da comparação com padrões de corpos, culturalmente difundidos como os mais adequados, em especial, pelos meios de comunicação (POULAIN, 2013). De acordo com Souza Junior et al., 2011), em função dos corpos constituírem relações humanas a partir das interações com o mundo, não há como desconsiderar a objetividade presente nas relações sociais e culturais. Para isso, os seguintes questionamentos foram feitos: Qual a influência dos fatores culturais diante dos casos de obesidade? Todos têm acesso e disponibilidade aos mesmos tipos de alimentos? O marketing influencia na escolha para se consumir certos tipos de alimentos? Quais os padrões de beleza que a mídia nos impõe como saudáveis? A sociedade e a família alertam sobre os riscos da obesidade?

Na sequência, a fim de abordar o conceito de sedentarismo, questionou-se na intervenção, quem praticava atividades físicas ou exercícios físicos; o que praticavam e qual o tempo destinado (DIAS et al., 2016). Diante das respostas dos/as estudantes, procederam-se pela problematização e apresentação de dados atuais do sedentarismo, no Brasil, os quais indicam que cerca de $45,9 \%$ da população brasileira é classificada como sedentária (MINISTÉRIO DO ESPORTE, 2017). Ainda, discutiu-se sobre os riscos advindos do sedentarismo e as causas à saúde dos/as mesmos/as, além das doenças que o acompanham. A maioria dos/as estudantes reportou a exemplos ligados ao contexto no qual estavam inseridos, com foco sempre nas relações familiares.

Foi importante ponderar, na intervenção, que nem sempre as pessoas têm oportunidades de tempo e espaços de lazer adequados e/ou suficientes para a prática dos exercícios físicos, sobretudo aquelas que se encontram na condição de trabalhadores/as com extensas jornadas de trabalho. Acrescido do tempo gasto com o deslocamento casa $\mathrm{X}$ trabalho e vice-versa. Esses são ingredientes presentes na sociedade brasileira, os quais parcela expressiva da população vivencia diariamente, fruto da avassaladora desigualdade social.

Para Veiga (2016), a desigualdade social se faz muito presente na história da população brasileira, estando associada à inferiorização das camadas populares e as dificuldades de apropriação dos bens produzidos pelo gênero humano, tais como os espaços 


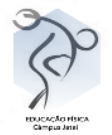

para a prática de exercícios físicos. Daí a defesa de uma perspectiva de educação escolar, alicerçada na pedagogia histórico-crítica, que seja capaz de problematizar a realidade na qual os/as estudantes estão inseridos/as, bem como apontar alternativas para a emancipação dos/as mesmos/as, em consonância com a busca permanente pela transformação social (SAVIANI, 2012; MARSIGLIA; MARTINS, LAVOURA, 2019).

Num segundo momento da intervenção, procedeu-se pelo recolhimento dos dados de IMC (RICARDO; ARAUJO, 2002) e do questionário do Bem Estar (NAHAS; BARROS; FRANCALACCI, 2000), com a intenção de que os/as estudantes calculassem os respectivos IMC, enquanto um pesquisador aferia a altura, o outro procedia pela aferição do peso corporal. Após, explicaram-se os fundamentos para se obter o IMC, acompanharam-se a realização dos cálculos e os/as estudantes responderam ao questionário do Bem Estar, individualmente. Na sequência, são apresentados alguns dados referentes às informações coletadas, sendo os primeiros ligados ao IMC dos/as participantes da pesquisa (Tabela 2) e os seguintes, a um recorte de dados obtidos por meio do Pentáculo do Bem Estar. Vale apontar que esses dados foram socializados individualmente e coletivamente, respeitando-se o sigilo identitário dos/as participantes.

Tabela 2. IMC dos/as participantes da pesquisa

\begin{tabular}{lc}
\hline Estados Nutricionais & Dados em Porcentagem \% \\
\hline Magreza moderada & 5.26 \\
Magreza leve & 15.78 \\
Saudável & 42.10 \\
Sobrepeso & 26.31 \\
Obesidade Grau I & 10,55 \\
\hline \multicolumn{2}{c}{ Fonte: Pesquisa de campo (2017) }
\end{tabular}

Foi possível constatar que 21,04 \% dos/as estudantes têm seu estado nutricional relacionados à magreza e 42,10\% encontram-se num estado nutricional saudável. Porém, $36,86 \%$ dos/as estudantes se encaixam nos estados de sobrepeso e obesidade grau I. Tais dados puderam ser analisados em consonância com a tabela 3.

Tabela 3 - Aspectos nutricionais dos/as estudantes 


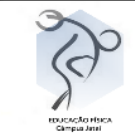

\begin{tabular}{lcccc}
\hline Perguntas & Nunca (\%) & Raramente (\%) & Quase Sempre (\%) & Sempre (\%) \\
\hline $\begin{array}{l}\text { A- Sua alimentação } \\
\text { diária inclui ao menos }\end{array}$ & 15,80 & 47,36 & 15,79 & 21,05 \\
$\begin{array}{l}5 \text { porções diárias de } \\
\text { frutas e verduras? }\end{array}$ & & & & \\
$\begin{array}{l}\text { B- Você evita ingerir } \\
\text { alimentos gordurosos } \\
\text { (carnes gordas, frituras) }\end{array}$ & 26,31 & 42,10 & 26,31 & 5,28 \\
$\begin{array}{l}\text { e doces? } \\
\text { C- Você faz de 4 a 5 } \\
\text { refeições variadas ao } \\
\text { dia, incluindo café da } \\
\text { manhã completo? }\end{array}$ & 15,80 & 26,31 & & \\
\hline
\end{tabular}

Fonte: Pesquisa de campo (2017)

Os resultados apontaram que, raramente, os/as estudantes, participantes desta pesquisa, incluem em sua alimentação diária, frutas e verduras, totalizando 47,36\% das respostas, acrescido de $15,80 \%$ que nunca o fazem. Ainda, nesse contexto, $42,10 \%$ dos/as estudantes apontaram que raramente evitam alimentos gordurosos, tais como carnes gordas, frituras e doces. E, somente, 36,84\% dos/as estudantes realizam ao menos cinco refeições diárias.

Geralmente, a dieta de muitos adolescentes se caracteriza por alimentos de valor nutricional baixo. Optam por alimentos com teor muito alto de gordura saturada e colesterol, além da grande quantidade de sal e açúcar que são ingeridas diariamente (ALVES et al., 2018; CASTRO et al., 2018). Tais dados vão ao encontro de dados identificados no contexto português, já que a diminuição das cinco refeições diárias contribui para um aumento dos índices de sobrepeso e obesidade, uma vez que as refeições intermediárias constituem-se como oportunidade de consumo de alimentos saudáveis, tais como as hortícolas, frutas e laticínios (ALVES et al., 2018)

A questão alimentar e nutricional precisa ser entendida a partir da problematização da alimentação como um direito humano e social da população brasileira, diante das emergentes demandas geradas para o atendimento das necessidades humanas. A contradição capital-trabalho é capaz de determinar quadros de carências e desequilíbrios nutricionais que são evidências de um mesmo fenômeno social: a insegurança alimentar e nutricional. Esta, ora se manifesta como desnutrição e outros agravos decorrentes de carências 


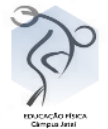

nutricionais, ora como obesidade ou outra doença crônica não transmissível (PINHEIRO; FREITAS; CORSO， 2004; BARATA， 2009; PINHEIRO; CARVALHO， 2010; BAGRICHEVSKY et al., 2013; NOGUEIRA et al., 2014).

Em relação à prática da atividade física, na Tabela 4, chamou atenção o fato de que apenas $21,05 \%$ dos/as estudantes praticam ao menos 30 minutos de atividade física de modo intenso ou moderado, cinco ou mais dias na semana. Quanto aos exercícios que envolvem força e/ou alongamento, 31,57\% disseram que nunca o fazem, mesmo percentual dos/as que realizam esse tipo de atividade com frequência (31,57\%). Diante do questionamento, se caminham ou pedalam como meio de transporte, e se usam escadas ao invés de elevadores, $42,10 \%$ destacaram raramente ter esse hábito, mesmo percentual dos/as que apontaram preferir tais meios.

Tabela 4 - Aspectos relacionados à prática de Atividades Físicas

\begin{tabular}{|c|c|c|c|c|}
\hline Perguntas & Nunca (\%) & Raramente (\%) & Quase Sempre (\%) & Sempre (\%) \\
\hline $\begin{array}{l}\text { D - Você realiza ao menos } 30 \\
\text { minutos de atividades físicas } \\
\text { moderadas ou intensas, de } \\
\text { forma contínua ou acumulada, } \\
5 \text { ou mais dias na semana? }\end{array}$ & 36,85 & 36,84 & 5,26 & 21,5 \\
\hline $\begin{array}{l}\text { E - Ao menos duas vezes por } \\
\text { semana você realiza exercícios } \\
\text { que envolvam força e } \\
\text { alongamento muscular? } \\
\text { F - No seu dia-a-dia, você } \\
\text { caminha ou pedala como meio }\end{array}$ & 31,57 & 10,55 & 26,31 & 31,7 \\
\hline $\begin{array}{l}\text { de transporte } \\
\text { preferencialmente, usa as } \\
\text { escadas ao invés do elevador? }\end{array}$ & 10,54 & 42,10 & 5,26 & 42,10 \\
\hline
\end{tabular}

Fonte: Pesquisa de campo (2017)

Conforme São Paulo (2014), os níveis de atividade física podem reduzir o risco de doenças hipocinéticas, tais como a hipertensão e a obesidade. Por sua vez, os baixos níveis de atividade física podem contribuir de forma indireta para o surgimento de quadros de diabetes associados ao ganho de peso e, consequentemente, ao acúmulo de gordura corporal (OMS, 


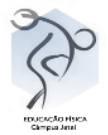

2000, 2005; ORGANIZAÇÃO PAN-AMERICANA DE SAÚDE, 2003; PALMA, 2008; CASTRO et al., 2018).

Diante de tais dados, problematizou-se com os estudantes sobre a necessidade de incorporarem a atividade física em seu cotidiano, bem como de exigirem do poder público, espaços destinados ao lazer da população local, como um meio de fazerem valer seus direitos, assegurados na Constituição Federal (BRASIL, 1988). Dimensão essa que deve estar atrelada a um coletivo maior. "Sua ressignificação precisa extrapolar os limites da individualidade e impregnar-se de concepções mais densas, sensíveis à dimensão coletiva, política, subjetiva, que atravessam e demarcam (e muitas vezes, restringem) as potencialidades de nossa condição existencial” (BAGRICHEVSKY et al., 2013, p. 507).

Sobre o item que versava obter informações sobre o meio social dos/as participantes, na Tabela 5 é possível constatar que 57,89\% dos participantes sempre procuram cultivar amigos e estão felizes com seus relacionamentos. Porém, 42,10\% destacaram que raramente o lazer é composto por reuniões com amigos, atividades esportivas em grupo ou participação em associações, acrescido de $21,05 \%$ que escolheram a opção "nunca". Por fim, $36,84 \%$ apontaram não serem ativos/as em suas comunidades e não buscam meios de se sentirem úteis em seu ambiente social.

Tabela 5 - Aspectos ligados ao relacionamento social

\begin{tabular}{|c|c|c|c|c|}
\hline Perguntas & Nunca $(\%)$ & Raramente (\%) & Quase Sempre (\%) & Sempre $(\%)$ \\
\hline $\begin{array}{l}\text { G - Você procura cultivar } \\
\text { amigos e está satisfeito com } \\
\text { seus relacionamentos? } \\
\text { H - Seu lazer inclui reuniões }\end{array}$ & 0 & 10,54 & 10,54 & 57,89 \\
\hline \begin{tabular}{lrr} 
com amigos, & \multicolumn{2}{c}{ atividades } \\
esportivas em & grupo ou \\
participação & & em \\
associações? & &
\end{tabular} & 21,05 & 42,10 & 15,80 & 21,05 \\
\hline $\begin{array}{l}\text { I - Você procura ser ativo } \\
\text { em sua comunidade, } \\
\text { sentindo-se útil no seu } \\
\text { ambiente social? }\end{array}$ & 36,84 & 10,54 & 26,31 & 26,31 \\
\hline
\end{tabular}

Fonte: Pesquisa de campo (2017) 
Os aspectos ligados aos relacionamentos interpessoais foram destacados para os/as estudantes, como expressões da vida em sociedade e fundamentais no processo de desenvolvimento humano. É papel da educação escolar e do componente curricular de Educação Física cultivar a importância do outro e da constituição de uma coletividade plural e heterogênea. Como sinaliza Waissmann (2003, p. 55), "o grupo, ao se constituir enquanto um todo de indivíduos" apresenta a apropriação e objetivação de "propriedades, por vezes, não existentes em cada indivíduo, mas que surgem a partir da experiência do grupo".

Tal dimensão deve permear os momentos de lazer e de socialização, via atividades esportivas e físico-corporais. Essas que são entendidas "como meio de relevância para a promoção do bem-estar e da saúde das coletividades, no que não se incluem práticas que sirvam como fator de amplificação de desigualdades" (WAISSMANN, 2003, p. 72). Corrobora com tal afirmação, o conceito de condições de saúde, noção estruturante do campo da Saúde Coletiva, usada para demarcar os elementos que se colocam como imprescindíveis, e que garantem a um coletivo de pessoas viver dignamente (BAGRICHEVSKY et al., 2013).

Por fim, após realizar um levantamento das percepções dos/as estudantes sobre as intervenções desenvolvidas averiguaram-se exemplos de respostas que valorizavam as ações desenvolvidas, e o quanto as ações com esse caráter contribuem para a apropriação e objetivação de conceitos científicos, capazes de elucidar as características da prática social que deve ser apreendida em suas diferentes contradições, auxiliando-os/as na superação de concepções sincréticas em sintéticas.

\section{CONSIDERAÇÕES FINAIS}

Embora as ações interventivas tenham sido desenvolvidas num curto espaço de tempo, esta investigação reforça o papel fundamental da Educação Física, no ensino médio, a fim de conduzir os/as estudantes a refletirem sinteticamente sobre a construção da desigualdade social no contexto brasileiro, esta que impede parcela expressiva da população se aproprie das objetivações produzidas pelo gênero humano, tais como os alimentos, as dimensões ligadas ao lazer e a prática de exercícios físicos. 
Os conteúdos presente no currículo do estado de São Paulo, ligados aos temas da obesidade e do sedentarismo, embora sejam pontuais, devem ser apresentados de forma contextualizada. As interpretações dos referidos conceitos não podem estar desvinculadas de uma leitura crítica dos determinantes históricos, sociais e culturais que exercem influências nesse processo, a exemplo da metodologia de ensino crítico-superadora, que tem como base a pedagogia histórico-crítica.

Partindo das intervenções na escola e nos debates gerados com os/as estudantes, em especial, diante dos conceitos de obesidade e sedentarismo, evidenciaram-se argumentos ainda muito pautados no senso comum. Impera a lógica de culpabilização pelo estado de saúde que se encontram, bem como de seus familiares.

No que tange aos instrumentos de pesquisa utilizados, os resultados apontaram que os/as estudantes optam por alimentos ricos em calorias e pobres em nutrientes, alimentos estes prejudiciais à saúde. Poucos são os que realizam ao menos cinco refeições diárias. Uma pequena parcela disse realizar atividades físicas frequentemente, aspecto que evidencia o alto índice de sedentarismo entre os jovens. Tais achados estão circunscritos a um pequeno universo investigativo, todavia, mesmo assim, não podem ser olhados isoladamente, senão em consonância com os fatores sociais e culturais que influenciam esse processo.

Por fim, esta pesquisa interventiva, em caráter de iniciação científica, oportunizou aos estudantes da licenciatura em Educação Física, maior contato com a futura realidade profissional, além do processo de aproximação entre universidade e escola, dimensão que deve ser, ainda, mais fortalecida no processo de formação inicial nas diferentes áreas do conhecimento.

\section{REFERÊNCIAS}

ALVES, Ana et al. Relação entre refeições intermédias e consumo alimentar em adolescentes portugueses. AdolesCiência, Bragança-PT, v. 5, n. 1, p. 23-32, nov. 2018. Disponível em: https://www.adolesciencia.ipb.pt/index.php/adolesciencia/issue/view/8. Acesso em: 18 fev. 2019.

BARATA, Rita Barradas. Como e por que as desigualdades sociais fazem mal à saúde. Rio de Janeiro: Editora FIOCRUZ, 2009. 


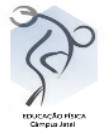

BARBOSA, Vera Lucia Perino. Prevenção da obesidade na infância e na adolescência. 2 ed. Barueri: Manole, 2008.

BAGRICHEVSKY, Marcos et al. Desigualdades sociais em saúde e práticas corporais: um exercício singular de análise. Saúde e Sociedade, São Paulo, v. 22, n. 2, p. 497510, jun. 2013 . Disponível em: http://dx.doi.org/10.1590/S0104-12902013000200019. Acesso em: 12 fev. 2019.

CABALLERO, Benjamin. The global epidemic of obesity: an overview. Epidemiologic Reviweus, v. 29, p. 1-5, jun. 2007. Disponível em: https://academic.oup.com/epirev/article/29/1/1/444345. Acesso em: 17 fev. 2019.

CASTRO, Jessica Marliere et al. Prevalence of overweight and obesity and the risk factors associated in adolescents. Revista Brasileira de Obesidade, Nutrição e Emagrecimento, v. 12, n. 69, p. 84-93, jan./fev. 2018. Disponível em:

http://www.rbone.com.br/index.php/rbone/article/view/657/511. Acesso em: 17 fev. 2019.

BRITO, Irma et al. Fatores associados ao consumo de álcool na adolescência, em função do género. Psic., Saúde \& Doenças, Lisboa, v. 16, n. 3, p. 392-410, dez. 2015. Disponível em: http://www.scielo.mec.pt/scielo.php?script=sci arttext\&pid=S1645-00862015000300010. Acesso em: 27 nov. 2017.

CARNEIRO, Carolina de Souza et al. Excesso de peso e fatores associados em adolescentes de uma capital brasileira. Rev. Bras. Epidemiol, São Paulo, v. 20, n. 2, p. 260-

273, June 2017 . Disponível em: http://www.scielo.br/pdf/rbepid/v20n2/1980-5497-rbepid20-02-00260.pdf. Acesso em: 31 out. 2017

CASTELlANi FILHO, Lino et al. Metodologia do ensino de Educação Física. 2. ed. São Paulo: Cortez, 2012.

CUREAU, Felipe Vogt et al.Sobrepeso/obesidade em adolescentes de Santa Maria-RS: prevalência e fatores associados. Rev. Bras. Cineantropom. Desempenho Hum, Florianópolis, v. 14, n. 5, p. 517-526, 2012. Disponível em: http://www.scielo.br/scielo.php?script=sci arttext\&pid=S198000372012000500003\&lng=en\&nrm=iso. Acesso em: 28 out. 2017.

DIAS, Graziany Penna et al. Pedagogia histórico-crítica, cultura corporal, saúde e atividade física: aspectos teórico e metodológicos para o ensino médio. Nuances: estudos sobre educação, Presidente Prudente, v. 27, n. 1, p. 165-186, jan./abr. 2016. Disponível em: http://dx.doi.org/10.14572/nuances.v27i1.3958. Acesso em: 12 set. 2017.

GARCIA JUNIOR, Jair Rodrigues Garcia. Dieta dos 10 passos: o emagrecimento definitivo. Bela Vista-São Paulo: Phorte Editora, 2007. 


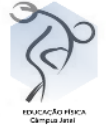

MARSIGLIA, Ana Carolina Galvão; MARTINS, Lígia Márcia; LAVOURA, Tiago Nicola. Rumo à outra didática histórico-crítica: superando imediatismos, logicismos formais e outros reducionismos do método dialético. HISTEDBR-online, Campinas, v. 19, e-019003, p. 1-28, 2019. Disponível em:

https://periodicos.sbu.unicamp.br/ojs/index.php/histedbr/article/view/8653380 . Acesso em: 19 mar. 2019. https://doi.org/10.20396/rho.v19i0.8653380

MARQUES-LOPES, Iva et al. Aspectos genéticos da obesidade. Rev. Nutr., Campinas, v. 17, n. 3, p. 327-338, set. de 2004. Disponível em:

http://www.scielo.br/scielo.php?script=sci arttext\&pid=S1415-

52732004000300006\&lng=pt\&nrm=iso. Acesso em: 25 de nov. 2017.

NAHAS, Markus Vinicius; BARROS, Mauro Virgílio Gomes; FRANCALACCI, Vanessa. O Pentáculo do bem-estar: base conceitual para avaliação do estilo de vida de indivíduos ou grupos. Revista Brasileira de Atividade Física e Saúde, Pelotas, v. 5, n. 2, p. 48-59, 2000. Disponível em: http://rbafs.org.br/RBAFS/article/view/1002/1156. Acesso em: 13 jun. 2017.

NOGUEIRA, Helena et al. Desigualdades sociais em saúde: o exemplo da obesidade infantil. Cadernos de Geografia, Coimbra-PT, n. 33, p. 133-140, 2014. Disponível em:

https://digitalis.uc.pt/pt-

pt/artigo/desigualdades_sociais_em_sa\%C3\%BAde_o_exemplo_da_obesidade_infantil. Acesso em: 17 fev. 2019.

ORGANIZAÇÃO PAN-AMERICANA DA SAÚDE (OPAS). Doenças crônicodegenerativas e obesidade: estratégia mundial sobre alimentação saudável, atividade física e saúde. Brasília: Organização Pan-Americana de Saúde. 2003.

PALMA, Alexandre. Sobrepeso, uma nova realidade no estado nutricional de pré-escolares de Natal (RN): epidemia ou pânico moral? Rev. Assoc. Med. Bras. São Paulo, v. 54, n. 4, p. 293-295, ago. 2008. Disponível

em: http://www.scielo.br/scielo.php?script=sci_arttext\&pid=S010442302008000400009\&lng=en\&nrm=iso. Acesso em: 14 mai. 2017.

PINHEIRO, Anelise Rizzolo de Oliveira; CARVALHO, Maria de Fátima Cruz Correia de. Transformando o problema da fome em questão alimentar e nutricional: uma crônica desigualdade social. Ciênc. saúde coletiva, Rio de Janeiro, v. 15, n. 1, p. 121-130, jan. 2010. Disponível em: http://www.scielo.br/scielo.php?script=sci_arttext\&pid=S141381232010000100018\&lng=en\&nrm=iso. Acesso em: 29 nov. 2017.

PINHEIRO, Anelise Rízzolo de Oliveira; FREITAS, Sérgio Fernando Torres de; CORSO, Arlete Catarina Tittoni. Uma abordagem epidemiológica da obesidade. Rev. Nutr. Campinas, v. 17, n. 4, p. 523-533, dez. 2004. Disponível em: 


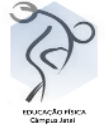

http://www.scielo.br/scielo.php?script=sci arttext\&pid=S1415-

52732004000400012\&lng=en\&nrm=iso. Acesso em: 09 jun. de 2017.

PINHO, Lucinéia de; BOTELHO, Ana Cristina de C.; CALDEIRA, Antônio Prates. Fatores associados ao excesso de peso em adolescentes de escolas públicas no norte de Minas Gerais. Rev. paul. Pediatr. São Paulo, v. 32, n. 2, p. 237-243, jun. 2014. Disponível em: http://www.scielo.br/scielo.php?script=sci arttext\&pid=S010305822014000200237\&lng=en\&nrm=iso. Acesso em: 14 mai. 2017.

POULAIN, Jean-Pierre. Sociologia da obesidade. São Paulo: Editora Senac São Paulo, 2013.

RICARDO Djalma Rabelo; ARAUJO, Claudio Gil Soares de. Índice de Massa Corporal: um questionamento científico baseado em evidências. Arq. Bras. Cardiologia, Rio de Janeiro, v.79, n.1, p. 61-69, set., 2002. Disponível em: https://www.researchgate.net/publication/200138093_Indice_de_massa_corporal_Um_questi onamento cientifico baseado em evidencias. Acesso em: 19 nov. 2017.

SAVIANI, Dermeval. Escola e democracia. 42 ed. Campinas: Autores Associados, 2012.

SILVA JUNIOR, Laércio M. et al. Prevalência de excesso de peso e fatores associados em adolescentes de escolas privadas de região urbana na Amazônia. Rev. paul. Pediatr, São Paulo, v. 30, n. 2, p. 217-222, jun. 2012. Disponível em:

http://www.scielo.br/scielo.php?script=sci arttext\&pid=S010305822012000200010\&lng=en\&nrm=iso. Acesso em: 14 mai. 2017.

SOUZA JUNIOR, Marcílio et al. Coletivo de autores: a cultura corporal em questão. Rev. Bras. Ciênc. Esporte (Impr.), Porto Alegre, v. 33, n. 2, p. 391-411, jun. 2011. Disponível em: http://www.scielo.br/scielo.php?script=sci arttext\&pid=S010132892011000200008\&lng=en\&nrm=iso. Acesso em: 28 nov. 2017.

TAFFAREL, Celi Zulke. Pedagogia histórico-crítica e metodologia de ensino críticosuperadora da Educação Física: nexos e determinações. Nuances: estudos sobre educação, Presidente Prudente, v. 27, n. 1, p. 05-23, jan./abr. 2016. Disponível em: http://revista.fct.unesp.br/index.php/Nuances/article/view/3962 . Acesso em: 15 jul. 2018. http://dx.doi.org/10.14572/nuances.v27i1.3962

TAVARES, Telma Braga; NUNES, Simone Machado; SANTOS, Mariana de Oliveira. Obesidade e qualidade de vida: revisão da literatura. Rev. Med. Minas Gerais, v. 20, n. 3, p. 359-366, 2010. Disponível em: http://rmmg.org/artigo/detalhes/371. Acesso em: 14 dez. 2018.

VEIGA, Cynthia Greive. Discriminação social e desigualdade escolar na história política da educação brasileira (1822-2016): alguns apontamentos. Hist. Educ, Santa Maria, v. 21, n. 53, p. 158-181, dez. 2017. Disponível em: 


\section{REFLECTIONIS

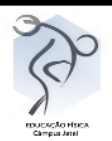

http://www.scielo.br/scielo.php?script=sci arttext\&pid=S223634592017000300158\&lng=en\&nrm=iso. Acesso em: 19 nov. 2017.

WAISSMANN, William. Desigualdade social e atividade física. In: BRAGRICHEVSKY, Marcos; PALMA, Alexandre; ESTEVÃO, Adriana. A saúde em debate na Educação Física. Edibes: Blumenau, 2003. p. 53-78.

WORLD HEALTH ORGANIZATION. Obesity: preventing and managing the global epidemic. Report of a World Health Organization Consultation. Geneva: World Health Organization, 2000.

WORLD HEALTH ORGANIZATION. Nutrition in adolescence - Issues and Challenges for the Health Sector: Issues in Adolescent Health and Development. Geneva: World Health Organization, 2005. 